\title{
THORACOSCOPIC APPROACH FOR BIOPSY OF THE LATISSIMUS DORSI CARDIOMYOPLASTY WRAP
}

Melissa A. Bochner, MBBS, FRACS, Regina Crameri, BAppSc (Hons), Yi Fei Huang, MD, PhD, Osamu Kawaguchi, MD, PhD, Russell Carrington, BAppSc, Christopher Horam, CertAnTech, Peter Brady, MBBS, FRACS, and Stephen N. Hunyor, MBBS, MTM, FRACP, FACC,

St. Leonards, New South Wales, Australia

Despite its use in clinical practice for more than 10 years, the operation of latissimus dorsi dynamic cardiomyoplasty still poses many unanswered questions regarding its efficacy, mechanism of action, and optimal management of the chronically paced skeletal muscle. ${ }^{1}$ Whereas some investigators have described isolated postmortem changes in human studies ${ }^{2}$ and single biopsy terminal results in animal studies, ${ }^{3}$ the time course of histologic and histochemical changes in the latissimus dorsi muscle after cardiomyoplasty has not been documented. The ability to perform minimally invasive biopsy of the latissimus dorsi muscle wrap would both facilitate research in this area and potentially aid in the management of patients with poor hemodynamic status after cardiomyoplasty. We have therefore examined the applicability of thoracoscopic biopsy of the latissimus dorsi muscle after its use in cardiomyoplasty in the sheep.

The study was approved by the Animal Care and Ethics Committee of our institution, and animals received humane care in compliance with the "Principles of Laboratory Animal Care" formulated by the National Society for Medical Research and the "Guide for the Care and Use of Laboratory Animals" prepared by the Institute of Laboratory Animal Research and published by the National Institutes of Health (NIH Publication No. 86-23, revised 1985). All operations were performed with the animal under general anaesthesia. Latissimus dorsi cardiomyoplasty was performed on six sheep. A standard open technique through a left thoracotomy was used. ${ }^{4}$ Baseline muscle biopsy specimens were taken at each procedure. The animals were nursed in a postoperative cage that allows invasive monitoring to continue until they are in a stable condition. Postoperative care included parenteral and enteral analgesia and prophylactic antibiotics.

From the Cooperative Research Centre for Cardiac Technology, Block 4, Royal North Shore Hospital, St. Leonards, New South Wales, Australia

Received for publication Sept. 10, 1997; accepted for publication Oct. 7, 1997.

Address for reprints: Dr. Melissa A. Bochner, c/o Professor S. N. Hunyor, Cooperative Research Centre for Cardiac Technology, Block 4, Level 3, Royal North Shore Hospital, St. Leonards, N.S.W., 2065, Australia.

J Thorac Cardiovasc Surg 1998;115:958-9

Copyright (c) 1998 by Mosby, Inc.

$0022-5223 / 98 \$ 5.00+0 \quad \mathbf{1 2 / 5 4 / 8 6 7 1 9}$
Thoracoscopic biopsy specimens of the in situ latissimus dorsi wrap were taken 6,12 , and 18 weeks after the initial operation, with a total of 18 thoracoscopic procedures performed in the six months. Standard video-assisted thoracoscopy equipment was used (Smith \& Nephew Endoscopy, Inc., Andover, Mass.), and all procedures were performed by means of twolung ventilation. After the animal had been positioned on the right side, three left-sided port-access incisions were made for the camera $(12 \mathrm{~mm})$ and two operating ports $(5 \mathrm{~mm})$. Postoperative adhesions between the lung, diaphragm, and chest wall were carefully divided, and the left aspect of the pedicle and wrap were exposed. In each instance, the wrap was able to be assessed for position, contraction, and muscle bulk. By means of sharp dissection, and with minimal crushing of the tissue, biopsy specimens were taken from the proximal part of the muscle near the pedicle and from the midportion of the muscle. The mean sample weight was $134 \mathrm{mg}$ (range 55 to $225 \mathrm{mg}$ ), and two samples were taken from each site at each procedure. Previous biopsy sites were able to be identified and avoided. With subsequent procedures, increased adhesion formation and the development of a capsule of fibrofatty tissue around the wrap was noted. Despite this, biopsy specimens of sufficient size (greater than 300 fibers) and quality to provide both complex histochemical data and tissue for protein analysis were able to be taken in all 18 procedures. Fig. 1 shows a representative thoracoscopic

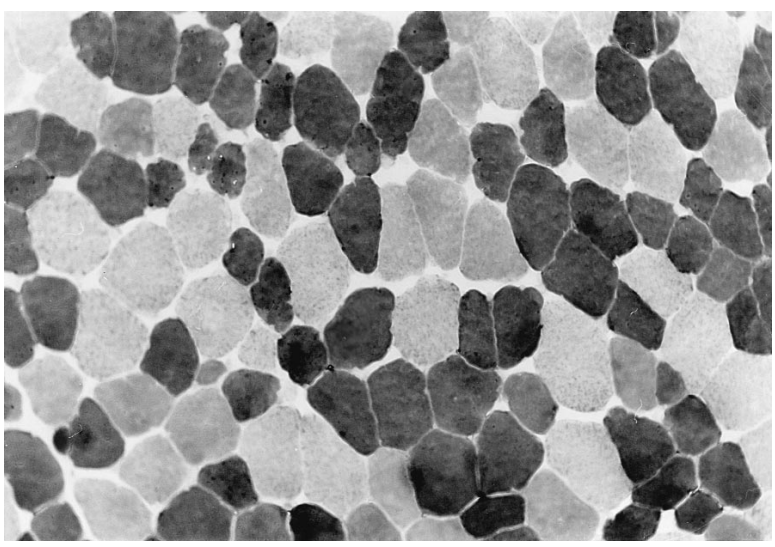

Fig. 1. Representative thoracoscopic biopsy sample stained with myosin adenosinetriphosphatase at $\mathrm{pH} 4.7$ (magnification $\times 200)$. 
biopsy sample stained with myosin adenosinetriphosphatase at $\mathrm{pH} 4.7$ (magnification $\times 200$ ).

The animals tolerated the thoracoscopic procedures well, with no deaths. All animals were extubated at the end of the procedure and were standing, eating, and drinking without apparent discomfort within 2 hours. In three animals, air leaks developed after dissection of lung adhesions; all three leaks resolved spontaneously and required less than 6 hours of underwater seal drainage. Chest drainage was not required in the other procedures.

There was no other morbidity.

In conclusion, we have found thoracoscopic biopsy to be a useful tool in the investigation of the changes occurring in the latissimus dorsi muscle after cardiomyoplasty. The procedure is well tolerated and is able to be performed sequentially in the same animal. There is potential for this technique to be used in further animal research and as an adjunct in the management of difficult clinical cases.
We acknowledge the technical assistance of Mr. R. Kearns, Ms. C. Philips, and Ms. J. Hardy.

\section{REFERENCES}

1. Magovern GJ, Simpson KA. Clinical cardiomyoplasty: review of the ten-year United States experience. Ann Thorac Surg 1996;61:413-9.

2. Magovern GJ, Heckler FR, Park SB, Christlieb IY, Liebler GA, Burkholder JA, et al. Paced skeletal muscle for dynamic cardiomyoplasty. Ann Thorac Surg 1988;45:614-9.

3. Lucas CMHB, Van der Veen FH, Cheriex EC, Lorusso R, Havenith M, Penn OCKM, et al. Long term follow up (12 to 35 weeks) after dynamic cardiomyoplasty. J Am Coll Cardiol 1993;22:758-67.

4. Carpentier A, Chachques J-C. Cardiomyoplasty: surgical technique. In: Carpentier A, Chachques JC, Grandjean P, editors. Cardiomyoplasty. 1st ed. Mount Kisco [NY]: Futura; 1991. p. $105-22$. 